\title{
O FIM DO TRABALHO FORÇADO: UMA UTOPIA POSSÍVEL
}

\author{
Celso Ricardo Peel Furtado de Oliveira ${ }^{1}$ \\ Wagner Camargo Gouveia ${ }^{2}$
}

Resumo: O presente artigo é resultado de pesquisa bibliográfica jurídico-teórica, com enfoque no método dedutivo para fins de abordagem do tema para defender que a abolição do trabalho forçado e escravo garantido não só pelo ordenamento nacional, bem como pelos tratados internacionais, deve ser aplicado de ofício pelos operadores do direito e pelo Estado, pela utilização do controle de convencionalidade.

Palavras-chaves: trabalho forçado; direitos humanos; empresas transnacionais; controle de convencionalidade.

\section{THE END OF FORCED LABOR: A POSSIBLE UTOPIA}

Abstract: This article is the result of a legal-theoretical bibliographic research, focusing on the deductive method for the purpose of defending that the abolition of forced and slave labor, guaranteed not only by national law, as well as by international treaties, should be applied ex officio by law operators and by the State, through the use of conventionality control.

Keywords: forced labor; human rights; transnational companies; conventionality control.

\section{Introdução}

Apesar da Lei 3353, de 13 de maio de 1888, assinada pela Princesa Isabel, ter decretada a extinção da escravidão, passados mais de 130 anos, o Brasil não está livre do trabalho escravo, forçado e obrigatório.

Em pleno século 21, a eliminação do trabalho forçado continua sendo um desafio para os Estados e a sociedade, uma vez que além de se caracterizar como uma das violações mais graves do direito fundamental de liberdade é também uma das principais causas de pobreza, desigualdade social e obstáculo ao desenvolvimento sustentável.

\footnotetext{
${ }^{1}$ Desembargador do Tribunal Regional do Trabalho de São Paulo. Professor Universitário. Mestre em Direito pela UNISANTA e Doutorando em Direito pela UNINOVE - celsopeel@ gmail.com.

${ }^{2}$ Delegado de polícia do Estado de São Paulo. Professor universitário. Mestre em Direito pela UNISANTA e doutorando em Direito pela UNINOVE - Wagner.camargogrupo@ yahoo.com.br.
} 
A Organização Internacional do Trabalho estima que cerca de 21 milhões de homens, mulheres e crianças estão em situação de trabalho forçado em todo o mundo, sendo que $90 \%$ (noventa por cento) explorados por empresas privadas.

As Nações Unidas, quer pela sua agência especializada em direito do trabalho, OIT com a aprovação de Convenções e Recomendações sobre o Trabalho Forçado ou diretamente com a adoção do Pacto Global para corporações transnacionais, tem como princípio abolir o trabalho forçado, trabalhando junto com as empresas visando o combate ao trabalho escravo.

As normas internacionais devem ter sua efetividade garantida por meio de políticas públicas e ainda pelo controle de convencionalidade, considerando a supralegalidade dos tratados de direitos humanos e sua aplicação de ofício pelos operadores do direito.

2.Trabalhadores em Condições Análogas à de Escravo no Brasil

Os dados relativos aos trabalhadores em condições análogas à de Escravo no Brasil são impressionantes, considerando o período compreendido entre a criação do Grupo Especial de Fiscalização Móvel GEFM, da Divisão de Fiscalização para Erradicação do Trabalho Escravo - Detrae, do Ministério do Trabalho e Emprego, de 1995 até 2020:

\begin{tabular}{|l|l|}
\hline $\begin{array}{l}\text { Trabalhadores em Condições Análogas à de Escravos } \\
\text { Encontrados pela Fiscalização }\end{array}$ & 56.021 \\
\hline Trabalhadores Formalizados no Curso da Ação Fiscal & 38.430 \\
\hline Número de Estabelecimentos Fiscalizados & 2.562 \\
\hline Guias de Seguro Desemprego Emitidas & 37.315 \\
\hline Verbas Rescisórias Recebidas pelos Trabalhadores & $\mathrm{R} \$ 110.216 .616,76$ \\
\hline
\end{tabular}

https://sit.trabalho.gov.br/radar/

Esses números poderiam ser maiores, se não houvesse uma política de desmonte das fiscalizações, o que pode ser constatado pela plataforma radar, ao verificar que em 2007 mais de 6 mil trabalhadores foram resgatados de condições análogas a de escravos enquanto os 
números dos últimos dois anos, 2020 e 2021, demonstram, respectivamente que apenas 936 e 314 trabalhadores foram resgatados.

Os números dos dois últimos anos não representam a realidade, considerando que o Ministério Público do Trabalho recebeu de 2016 a 2020 aproximadamente seis mil denúncias relacionadas a trabalho escravo, segundo dados da Coordenadoria Nacional de Combate ao Trabalho Escravo e Enfrentamento ao Tráfico de Pessoas - Conaete/MPT.

3. Portarias do Ministério do Trabalho.

O governo publicou em 2003, a portaria 1.153 estabelecendo procedimentos a serem cumpridos pelos auditores do trabalho na identificação e libertação dos trabalhadores submetidos a regime de trabalho forçado e condição análoga à de escravo.

Posteriormente, em 13 de outubro de 2017, foi publicada a Portaria 1.129, alterando o conceito de trabalho forçado, jornada exaustiva e condições análogas à de escravo.

A Portaria recebeu críticas de toda a sociedade, uma vez que acabou afrouxando o combate ao trabalho forçado e foi cassada em razão de liminar concedida pela Ministra Rosa Weber, por medida cautelar na arguição de descumprimento de preceito fundamental no. 489, do Distrito Federal.

Ante o exposto, forte no art. $5^{\circ}, \S 1^{\circ}$, da Lei $n^{\circ} 9.882 / 1999$, com o caráter precário próprio aos juízos perfunctórios e sem prejuízo de exame mais aprofundado quando do julgamento do mérito, defiro o pedido de liminar, ad referendum do Tribunal Pleno, para suspender, até o julgamento do mérito desta ação, os efeitos da Portaria do Ministério do Trabalho no ${ }^{\circ} 1.129$, de 13.10.2017.

Em face da decisão do Supremo Tribunal Federal, o governo editou a Portaria 1.293, de 28 de dezembro de 2017, revogando a anterior, o que levou a extinção da ADPF 489 por perda de objeto, uma vez que a nova regulamentação atingiu os anseios dos agentes sociais, considerando que invés de restringir as possibilidades de configuração da prática escravista, ampliou a possibilidade de caracterização de trabalho forçado ou análogo à escravidão, com 
definições de trabalho forçado; jornada exaustiva; condição degradante de trabalho; restrição por qualquer meio, de locomoção em razão de dívida contraída com empregador ou preposto, no momento da contratação ou no curso do contrato de trabalho, por cerceamento do uso de qualquer meio de transporte, manutenção de vigilância ostensiva e retenção de documentos ou objetos pessoais.

4. Emenda Constitucional no. 81, de 2014.

Em 05 de junho de 2014, com a Emenda Constitucional no. 81, foi dada nova redação ao art. 243 da Constituição Federal, passando a vigorar com a seguinte redação:

Art. 243. As propriedades rurais e urbanas de qualquer região do País onde forem localizadas culturas ilegais de plantas psicotrópicas ou a exploração de trabalho escravo na forma da lei serão expropriadas e destinadas à reforma agrária e a programas de habitação popular, sem qualquer indenização ao proprietário e sem prejuízo de outras sanções previstas em lei, observado, no que couber, o disposto no art. $5^{\circ}$.

A nova redação é um avanço no combate para abolir toda forma de trabalho forçado ou escravo, representando o cumprimento pelo Brasil dos compromissos internacionais assumidos ao ratificar os Tratados Internacionais sobre a Abolição do trabalho forçado.

Entretanto, o atual governo já sinalizou que não pretende regulamentar a nova emenda, que permitiria a expropriação de terras onde houvesse exploração de trabalho escravo uma vez que defende o Presidente da República que a Emenda Constitucional torna vulnerável a questão da propriedade privada, sinalizando a impunidade aos exploradores de mão-de-obra forçada.

A atitude do Chefe de Estado Brasileiro poderá ter consequências, em razão dos compromissos assumidos pelo país ao ratificar os Tratados Internacionais onde se comprometeu a adotar todas políticas públicas para abolir o trabalho forçado. 
A nova redação ao texto constitucional vai de encontro aos compromissos internacionais, com a expropriação das terras do violador do direito fundamental, desincentivando a utilização de trabalho forçado e escravo.

\section{Código Penal}

5.1. Mandado de criminalização. Punição.

Os mandados de criminalização atuam como mecanismos de ordem constitucional destinados ao legislador ordinário para que este legisle criminalizando determinada matéria. Esses mandados direcionam a atenção do legislador para as demandas tidas como fundamentais para a construção de uma sociedade embasada na dignidade da pessoa humana.

Tema de absoluta relevância, pois há uma ordem do poder constituinte originário de criar uma punição legislativa, seja de uma forma expressa, tácita ou convencional. A Constituição Federal é a origem dos mandados de criminalização, e não seu fim.

Para Antônio Carlos da Ponte define os mandados constitucionais de criminalização:

Os mandados constitucionais de criminalização indicam matérias sobre as quais o legislador ordinário não tem a faculdade de legislar, mas sim a obrigatoriedade de tratar, protegendo determinados bens ou interesse de forma adequada, e dentro do possível, integral. (PONTE: 2015)

Quando a própria Lei Maior determina a criação da punição, veda de forma expressa a redução a condição análoga à de escravo.

Nesse sentido, preceitua o artigo $5^{\circ}$, incisos XLVI e XLVII, afirmando que ninguém será submetido a tratamento desumano ou degradante em nosso país, garantindo-se a livre locomoção dos indivíduos, vedando-se qualquer tipo de discriminação atentatória aos direitos e liberdades fundamentais, bem como proibindo os trabalhos forçados. 
Dessa forma, nem mesmo pessoas julgadas e condenadas pela prática de delitos podem ser submetidas a trabalhados forçados.

Portanto, os mandados constitucionais de criminalização abrangem todo o sistema normativo e substancialmente tem seu peso evidenciado pelo Direito Penal, pois visam, em suma, o bem de todos e garantir a paz social. É neste ramo do Direito onde se tutela os bens imprescindíveis com maior coercibilidade, utilizando assim o princípio da fragmentariedade.

Se considerar que os mandados de criminalização estão atrelados a valores maiores, como a vida, honra, saúde, etc., todos consagrados na Constituição, constatam-se que todos eles são objeto de tutela penal.

Portanto, o legislador cumpriu seu papel e está expresso conforme visto acima.

\subsection{Do tipo penal.}

Por outro lado, na seara da prestação de serviços, o legislador em 2003, incluiu no código penal o artigo 149, com a seguinte redação:

Art. 149. Reduzir alguém a condição análoga à de escravo, quer submetendo-o a trabalhos forçados ou a jornada exaustiva, quer sujeitando-o a condições degradantes de trabalho, quer restringindo, por qualquer meio, sua locomoção em razão de dívida contraída com o empregador ou preposto.

O crime de redução a condição análoga à de escravo, consiste no fato de "reduzir alguém a condição análoga à de escravo, quer submetendo-o a trabalhos forçados ou a jornada exaustiva, quer sujeitando-o a condições degradantes de trabalho, quer restringindo, por qualquer meio, sua locomoção em razão de dívida contraída com o empregador ou preposto" (CP, art. 149, caput).

O bem jurídico tutelado é a liberdade de autodeterminação, consistente do direito de ir, vir e permanecer, ou seja, é o direito da pessoa humana em não ser submetida à servidão e ao poder de fato de outrem, esse objeto jurídico tem que ser efetivamente lesado, por ser crime de dano. 
Não se deve confundir com o objeto material, que é a pessoa humana reduzida à condição semelhante à de escravo, em razão da conduta criminosa do agente.

Como bem observa Guilherme de Souza Nucci, o dispositivo tem por finalidade:

\begin{abstract}
(...)atacar o grave problema brasileiro do 'trabalho escravo', muito comum em fazendas e zonas afastadas dos centros urbanos, onde trabalhadores são submetidos a condições degradantes de sobrevivência e de atividade laborativa, muitos sem a remuneração mínima estipulada em lei, sem os benefícios da legislação brasileira e, o que é pior, levados a viver em condições semelhantes a dos escravos. (NUCCI: 2012, p. 734)
\end{abstract}

Veja que o elemento objetivo traz o verbo "reduzir", logo qualquer pessoa pode cometer, assim como o "alguém", portanto isso caracteriza como crime comum, tanto no sujeito ativo, quanto no passivo, porém se mais de uma pessoa cometerem o crime, aplica a regra do concurso de pessoas do artigo 29 , do $\mathrm{CP}$, pois é um crime monossubjetivo.

Insta salientar que, esse empregador, pode ser preso em flagrante a qualquer momento, por ser crime permanente.

O sujeito passivo também pode ser qualquer pessoa vinculada a uma relação de trabalho.

Assim, sujeito ativo será o empregador que utiliza a mão de obra escrava. Sujeito passivo, a seu turno, será o empregado que se encontra numa condição análoga à de escravo.

Eventual consentimento do ofendido é irrelevante, pois o status libertatis constitui bem jurídico indisponível.

Importante mencionar que, o tipo penal traz vários atos na conduta típica, assim trata-se de crime plurissubsistente, que pode ser interrompido no meio, admitindo a figura da tentativa. 
Esse criminoso, relevante mencionar, pede um fazer, ação, comissivo, não admitindo a forma omissiva, além de ser uma forma vinculada, pelos meios de execução descritos no tipo penal.

A consumação consistente na imposição de trabalho excessivo ou em condições degradantes como também na privação da liberdade de locomoção da vítima em razão de dívida contraída com seu empregador, logo precisa desse resultado naturalístico, logo crime material.

Rogério Greco discorda e argumenta:

(...)após a nova redação do art. 149 do Código Penal, levada a efeito pela Lei 10.803, de 11 de dezembro de 2003, foram delimitados os sujeitos ativo e passivo do delito em estudo, devendo, agora, segundo entendemos, existir entre eles relação de trabalho.(GRECO: 2012, pp. 521-522)

O elemento objetivo do tipo penal está pelo núcleo reduzir, ou seja, converter ou transformar, cuja conduta típica consiste em reduzir uma pessoa humana a condição análoga à de escravo, submetendo-a a trabalhos forçados ou jornadas exaustivas, bem como a condições degradantes de trabalho.

A palavra "escravo" constitui elemento normativo do tipo, cujo significado deve ser extraído mediante uma valoração do magistrado no caso concreto, conhecido doutrinariamente como tipo aberto.

Sua tipificação ocorre sempre que presente quaisquer das seguintes condutas típicas:

a) Submeter à vítima a trabalhos forçados ou a jornada exaustiva, o agente emprega violência física ou moral e a vítima o executa contra sua vontade. $\mathrm{Na}$ jornada exaustiva, a duração do trabalho ultrapassa os limites legais deixando a vítima esgotada física e psiquicamente; 
b) Sujeitar a vítima a condições degradantes de trabalho, ocorre quando o ambiente de trabalho não assegura as condições legais mínimas, tornando-se humilhante para um ser humano livre e digno de respeito;

c) Restringir, por qualquer meio, a locomoção da vítima em razão de dívida contraída com o empregador ou preposto, por exemplo, quando o empregado se torna devedor, incapaz de honrar suas obrigações, ficando impedido de abandonar livremente seu local de trabalho;

d) Cercear o uso dos meios de transporte, com a finalidade de reter a vítima no local de trabalho, por exemplo, quando o empregador arbitrariamente retira o meio de transporte que levaria a vítima à cidade mais próxima, com a finalidade de retê-la em seu local de trabalho;

e) Manter vigilância ostensiva no local de trabalho ou se apoderar de documentos ou objetos pessoais da vítima, com a finalidade de retê-la no local de trabalho, cujo exemplo existe vigilância com a finalidade específica de manter a vítima em seu local de trabalho, pois, a vigilância, por si só, não caracteriza o crime. É o que ocorre também quando, com a mesma finalidade, o agente se apodera de documentos ou objetos pessoais da vítima.

Destarte, o crime em tela é de ação múltipla ou de conteúdo variado, sendo que a realização de uma só conduta já é suficiente para caracterizar o delito. Assim, a pluralidade de condutas, em relação à mesma vítima, é levada em conta na dosimetria da pena, porém, constitui crime único.

O magistrado ao proferir a sentença, na primeira fase da dosimetria da pena, majora essa pena pelas circunstâncias judiciais do artigo 59, do CP.

E esse tipo penal é um exemplo do conflito aparente de normas, utilizando o princípio da alternatividade. 
O crime é punido exclusivamente a título de dolo, consistente na vontade livre e consciente de exercer o domínio sobre a vítima, por meio das condutas incriminadas no tipo penal, suprimindo-lhe a liberdade de fato, pois o tipo penal silenciou a respeito, assim o elemento subjetivo do tipo não trouxe a punição na forma culposa.

Nas figuras equiparadas do $\S 1^{\circ}$, incisos I e II, exige-se, além do dolo, um especial fim de agir, representado pelas expressões: "com o fim de retê-lo no local de trabalho".

\section{Organização Internacional do Trabalho}

No plano internacional, já em 1930 foi aprovada a Convenção no. 29 sobre o trabalho forçado, ratificada e com vigência no Brasil a partir de 25 de abril de 1958, no qual se obrigou a suprimir o emprego do trabalho forçado ou obrigatório sob todas as suas formas, nos termos do art. $1^{\circ}$, da referida norma internacional.

Um dos aspectos mais relevantes da Convenção 29, foi a de definir trabalho forçado como "todo trabalho ou serviços exigidos de uma pessoa sob a ameaça de sanção e para a qual ela não se tenha oferecido espontaneamente", buscando abranger todas as possibilidades fáticas de trabalho forçado no mundo.

Posteriormente, a Organização Internacional do Trabalho, em 1957 foi aprovada a Convenção 105 sobre a Abolição do Trabalho Forçado, também ratificada e com vigência no Brasil, a partir de 18 de junho de 1966, segundo a qual, houve o compromisso de se a adotar medidas eficazes, no sentido da abolição imediata e completa do trabalho forçado ou obrigatório no país.

A Convenção 105, foi mais detalhada, pois além de assumirem os países o compromisso de suprir o trabalho forçado, também se comprometerem a não recorrer, nos termos do art. $1^{\circ}$.:

a) como medida de coerção, ou de educação política ou como sanção dirigida a 
pessoas que tenham ou exprimam certas opiniões políticas, ou manifestem sua oposição ideológica à ordem política, social ou econômica estabelecida; b) como método de mobilização e de utilização da mão-de-obra para fins de desenvolvimento

econômico; c) como medida de disciplina de trabalho; d) como punição por participação em greves; e) como medida de discriminação racial, social, nacional ou religiosa.

Em 2014, na $103^{\text {a }}$ Sessão da Conferência Internacional do Trabalho, da OIT, foram aprovados um Protocolo e uma Recomendação que complementam a Convenção no. 29 sobre o Trabalho Forçado, com vigência internacional a partir de 2016, trazendo medidas efetivas a serem tomadas pelos Estados Membros para ajudar na luta contra a eliminação efetiva de todas as formas de trabalho forçado.

O Protocolo, em razão da sua natureza de tratado internacional, com a ratificação, como toda Convenção da OIT é juridicamente vinculativo, tendo grande importância uma vez que exige dos Estados Membros medidas de prevenção, proteção e reparação para as vítimas do trabalho forçado.

Por outro lado, a Recomendação no. 203 veio no sentido de complementar, não só a Convenção no. 29 mas também o seu Protocolo, fornecendo orientações não vinculativas sobre medidas a serem adotadas em políticas públicas nacionais.

Infelizmente, referidos instrumentos internacionais até a presente data não foram ratificados pelo Brasil, não havendo nenhuma sinalização por parte do governo brasileiro, no sentido do interesse em de reunir aos quase 60 países que já ratificaram as referidas normas.

Ainda que não ratificados os dois últimos instrumentos de 2014, o Brasil assumiu o compromisso internacional de adotar políticas públicas no sentido de eliminação do trabalho forçado. Entretanto, o que temos assistido é a falta de interesse em combater o trabalho escravo, o que é público e notório, inclusive, com a declaração de não regulamentar a 
desapropriação das terras dos empresários que utilizam trabalhadores em situação análoga a de escravo, poderá sofrer nova reclamação perante a OIT.

Como é sabido, o país já tem em andamento duas reclamações em andamento, pelo não cumprimento pelo Brasil, da Convenção sobre a proteção aos povos indígenas e da Convenção sobre negociação coletiva uma vez que o combate ao trabalho forçado faz parte da Declaração dos Princípios Fundamentais da OIT.

7. Pacto Global das Nações Unidas para corporações transnacionais

A percepção da necessidade de um pacto global para as corporações transnacionais, surgiu no Fórum Econômico Mundial de Davos, pelo Secretário Geral das Nações Unidas e época, Kofi Annan, preocupado com os efeitos da globalização e o futuro do sistema capitalista.

Assim, foi lançado em 2000 o Pacto Global, com a intenção de trazer as empresas transnacionais para dentro das Nações Unidas, para a atuação conjunta na promoção de valores sociais e responsabilidade social das empresas, visando articular uma nova etapa do liberalismo que garantisse uma face humana ao capitalismo, com a adoção de dez princípios, entre eles o princípio de abolir o trabalho forçado.

Com efeito a articulação conjunta das Nações Unidas e corporações transnacionais, representa a maior iniciativa de sustentabilidade corporativa do mundo, com mais de 16 mil membros, entre empresas e organizações distribuídos em 69 redes locais que abrangem 160 países.

Apesar da adoção dos princípios pelas grandes corporações, ainda temos, especialmente no campo, a utilização de mão-de-obra escrava, o que leva a necessidade dos grandes grupos acompanharem toda a cadeia de produção, exigindo o cumprimento da abolição do trabalho forçado de ponta a ponta na atividade econômica. 
A responsabilidade social das empresas transnacionais, pela abolição do trabalho forçado, possibilitará que sejam reconhecidas como eficientes e cumprir as regras do Pacto Global das Nações e seus Objetivos de Desenvolvimento Sustentável, para implantação de um capitalismo humanista.

\section{Controle de Convencionalidade}

O controle de convencionalidade ainda é um instrumento relativamente pouco conhecido da doutrina brasileira e dos operadores do direito de um modo geral e a sua não utilização demonstra a dificuldade de compreensão de um direito como sistema e tem origem na necessidade de observância dos Tratados Internacionais, inclusive pelos Estados, constituindo-se como um meio de dar efetividade por parte do signatário.

Com efeito, o controle de convencionalidade foi integrado no direito brasileiro, a partir de 2008, com um novo tipo de controle das normas infraconstitucionais, tema que antes da EC 45/04 era totalmente desconhecido.

No dia 3/12/08 foi proclamada, pelo Pleno do STF (HC 87.585-TO e R 466.343-SP), uma das decisões mais históricas de toda sua jurisprudência, com o reconhecimento pelo Supremo que os tratados de direitos humanos valem mais do que a lei ordinária.

Segundo a decisão, caso o tratado de direitos humanos venha a ser aprovado pelas duas casas legislativas com quorum qualificado terá ele valor de EC. Fora disso, todos os demais tratados de direitos humanos vigentes no Brasil contam com valor supralegal, ou seja, valem mais do que a lei e menos que a Constituição.

Segundo Valério Mazzuoli, o controle de convencionalidade trata-se de:

Uma forma de compatibilização entre as normas de direito interno e os tratados de direitos humanos ratificados pelo governo e em vigor no país, implicando em verdadeiro controle de validade das normas internas do Estado, parametrizado pelos compromissos internacionais por ele assumidos, tendo por objeto a proteção de direitos humanos. (MAZZUOLI: 2011) 
Com o reconhecimento da natureza supralegal dos Tratados Internacionais de Direitos Humanos, os compromissos assumidos pelo país, com a ratificação dos instrumentos internacionais, podem ser exigidos, não só do pelo Estado mas também das empresas, por meio do controle de convencionalidade.

\section{Considerações Finais}

Da análise de todo o conjunto normativo nacional sobre a abolição do trabalho forçado, tanto interna, como o Código Penal e as Portarias do Poder Executivo, bem como internacional, traduzido pelos tratados internacionais de direitos humanos sociais trabalhistas da Organização Internacional do Trabalho, já temos instrumentos jurídicos para punição dos empresários que continuam adotando a prática de submeter indivíduos ao trabalho forçado.

As corporações transnacionais aderiram a esta luta, por meio do Pacto Global das Nações Unidas, com o reconhecimento que a eficiência empresarial passa obrigatória pela responsabilidade social e sustentabilidade.

Com efeito, o que falta é vontade política para atuação forte do governo, o que não ocorreu, em face de pronunciamento do chefe do Estado, no sentido de priorizar a propriedade privada sobre o respeito aos direitos humanos fundamentais, ao se negar a apresentar a regulamentação a desapropriação de terras dos empresários que foram flagrados utilizando mão-de-obra escrava.

Terminamos este ensaio, citando Eduardo Galeano:

A UTOPIA ESTÁ LÁ NO HORIZONTE.

ME APROXIMO DOIS PASSOS, ELA SE AFASTA DOIS PASSOS.

CAMINHO DEZ PASSOS E O HORIZONTE CORRE DEZ PASSOS.

POR MAIS QUE EU CAMINHE, JAMAIS ALCANÇAREI.

PARA QUE SERVE A UTOPIA?

SERVE PARA ISSO: 


\section{PARA QUE EU NÃO DEIXE DE CAMINHAR}

A utopia serve para que não desistamos de lutar pelo fim do trabalho forçado, na busca incansável do processo de desenvolvimento civilizatório.

Referências Bibliográficas

BRASIL.

Ministério do Trabalho e Previdência Social. Portaria no. 1.153, de 13 de outubro de 2003. Estabelece procedimentos a serem cumpridos pelos Auditores-Fiscais do Trabalho nas ações fiscais para identificação e libertação de trabalhadores submetidos a regime de trabalho forçado e condição análoga à de escravo visando à concessão do benefício do Seguro-Desemprego. Disponível em: http://www.normaslegais.com.br/legislacao/trabalhista/por_1153_14_10_2003.htm. Acesso em 20.09.2021.

Ministério do Trabalho e Previdência Social. Portaria MTB no 1.129, de 13 de outubro de 2017. Dispõe sobre os conceitos de trabalho forçado, jornada exaustiva e condições análogas à de escravo para fins de concessão de seguro-desemprego ao trabalhador que vier a ser resgatado em fiscalização do Ministério do Trabalho, nos termos do art. $2^{\circ}$-C da Lei $\mathrm{n}^{\circ}$ 7.998, de 11 de janeiro de 1990; bem como altera dispositivos da Portaria Interministerial MTPS/MMIRDH $\mathrm{n}^{\circ}$ 4, de 11 de maio de 2016. Disponível em: https://www.in.gov.br/materia/-/asset_publisher/Kujrw0TZC2Mb/content/id/19356195/do12017-10-16-portaria-n-1-129-de-13-de-outubro-de-2017-19356171. Acesso em: 20.09.2021. Ministério do Trabalho e Previdência Social. Portaria MTB no 1.293, de 28 de dezembro de 2017. Dispõe sobre os conceitos de trabalho em condições análogas à de escravo para fins de concessão de seguro-desemprego ao trabalhador que vier a ser resgatado em fiscalização do Ministério do Trabalho, nos termos do artigo $2^{\circ}$-C da Lei $n^{\circ} 7.998$, de 11 de janeiro de 1990, e trata da divulgação do Cadastro de Empregadores que tenham submetido trabalhadores à condição análoga à de escravo, estabelecido pela Portaria Interministerial MTPS/MMIRDH $\mathrm{n}^{\mathrm{o}}$ 4, de 11 de maio de 2016. Disponível em: https://www.in.gov.br/materia/-/asset publisher/Kujrw0TZC2Mb/content/id/1497798/do12017-12-29-portaria-n-1-293-de-28-de-dezembro-de-2017-1497794. Acesso em 20.09.2021. 
Supremo Tribunal Federal, Medida Cautelar na Arguição de Descumprimento de Preceito Fundamental $\mathbf{n}^{\mathbf{0}}$ 489, Distrito Federal, Rel ${ }^{\mathrm{a}}$ Min. Rosa Weber, Data de Julgamento: 23.10.2017. Disponível em: <https://d2f17dr7ourrh3.cloudfront.net/wpcontent/uploads/2017/10/ADPF-489_liminar_RW.pdf>. Acesso em: 20.09.2021.

Ministério do Trabalho e Previdência Social. Portaria Interministerial MTPS/MMIRDH $\mathrm{n}^{\circ}$ 4, de 11 de maio de 2016. Dispõe sobre as regras relativas ao cadastro de empregadores que tenham submetido trabalhadores a condições análogas à de escravo. Disponível em: https://www.in.gov.br/materia//asset_publisher/Kujrw0TZC2Mb/content/id/22805466/do1-2016-05-12-portariainterministerial-n-4-de-11-de-maio-de-2016-22805411. Acesso em 20.09.2021.

Constituição da República Federativa do Brasil de 1988. Disponível em: http://www.planalto.gov.br/ccivil_03/constituicao/constituicao.htm. Acesso em 10.09.2021.

Decreto-lei no. 2.848, de 07 de dezembro de 1940. (Código Penal) Disponível em: http://www.planalto.gov.br/ccivil_03/decreto-lei/del2848compilado.htm. Acesso em 10.09.2021.

Lei 3.3.53, de 13 de maio de 1888. (Lei Áurea) Disponível em: http://www.planalto.gov.br/ccivil_03/leis/lim/lim3353.htm. Acesso em 10.09.2021.

GRECO, Rogério. Curso de Direito Penal - Parte Especial - Volume II. São Paulo: Ímpetos, $9^{\mathrm{a}}$ ed., 2012, pp. 521-522.

MAZZUOLI, Valerio de Oliveira. O controle jurisdicional da convencionalidade das leis. $2^{\mathrm{a}}$ ed. rev., atual. e ampl. São Paulo: Editora Revista dos Tribunais. 2011

MINISTÉRIO PÚBLICO DO TRABALHO

Denúncias sobre trabalho escravo. Disponível em:

https://mpt.mp.br/pgt/noticias/em-cinco-anos-mpt-recebe-5-909-denuncias-sobre-trabalhoescravo. Acesso em 11.09.2021.

NUCCI, Guilherme de Souza. Código Penal Comentado. São Paulo: Revista dos Tribunais, $11^{\mathrm{a}}$ ed., 2012, p. 734. 
ORGANIZAÇÃO INTERNACIONAL DO TRABALHO

Convenção (nº 29) sobre o Trabalho Forçado, 1930. Disponível em: https://www.ilo.org/brasilia/convencoes/WCMS_235021/lang--pt/index.htm. Acesso em 20.09.2021.

Convenção (n. 105) sobre a Abolição do Trabalho Forçado, 1957. Disponível em: https://www.ilo.org/brasilia/convencoes/WCMS_235195/lang--pt/index.htm. Acesso em 20.09.2021.

Protocolo de 2014 relativo à Convenção sobre Trabalho Forçado, 1930. Disponível em: https://www.ilo.org/dyn/normlex/es/f?p=1000:11300:14872971711140::::P11300 INSTRU MENT SORT:1. Acesso em 20.09.2021.

Recomendação ( ${ }^{\circ}$. 203) sobre o Trabalho Forçado (Medidas Complementares), 2014. Disponível em: https://www.ilo.org/dyn/normlex/es/f?p=NORMLEXPUB:12100:0::NO::P12100_INSTRU MENT_ID:3174688. Acesso em 20.09.2021.

PONTE. Antônio Carlos da. Crimes Eleitorais. Saraiva: 2015.

PORTAL GI. Bolsonaro diz que emenda sobre trabalho escravo não será regulamentada em seu governo. Disponível em: https://g1.globo.com/mg/triangulo-mineiro/noticia/2021/05/01/bolsonaro-diz-que-emendasobre-trabalho-escravo-nao-sera-regulamentada-em-seu-governo.ghtml. Acesso em: 20.09.2021. 